\title{
Polymerization shrinkage stress of composite resins and resin cements - What do we need to know?
}

Carlos José SOARES(a)

André Luis FARIA-E-SILVA(b)

Monise de Paula RODRIGUES(a)

Andomar Bruno Fernandes VILELA(a)

Carmem Silvia PFEIFER(c)

Daranee TANTBIROJN(d)

Antheunis VERSLUIS(e)

(a) Universidade Federal de Uberlândia - UFU, Dental School, Department of Operative Dentistry and Dental Materials, Uberlândia, Minas Gerais, Brazil.

(b) Universidade Federal de Sergipe - UFS, Dental School, Department of Dentistry,

Aracaju, Sergipe, Brazil;

(c) Oregon Health and Science University OHSU, School of Dentistry, Department of Restorative Dentistry, Portland, OR, United

States of America

(d) University of Tennessee Health Science Center, College of Dentistry, Department of Restorative Dentistry, Memphis, TN, United States of America

(e) University of Tennessee Health Science Center, College of Dentistry, Department of Bioscience Research, TN, United States of America

Declaration of Interest: The authors certify that they have no commercial or associative interest that represents a conflict of interest in connection with the manuscript.

Corresponding author:

Carlos José Soares

E-mail: carlosjsoares@ufu.br

htips://doi.org/10.1590/1807-3107BOR-2017.vol31.0062

Submitted: May 21, 2017

Accepted for publication: May 22, 2017

Last revision: May 29, 2017
Abstract: Polymerization shrinkage stress of resin-based materials have been related to several unwanted clinical consequences, such as enamel crack propagation, cusp deflection, marginal and internal gaps, and decreased bond strength. Despite the absence of strong evidence relating polymerization shrinkage to secondary caries or fracture of posterior teeth, shrinkage stress has been associated with postoperative sensitivity and marginal stain. The latter is often erroneously used as a criterion for replacement of composite restorations. Therefore, an indirect correlation can emerge between shrinkage stress and the longevity of composite restorations or resin-bonded ceramic restorations. The relationship between shrinkage and stress can be best studied in laboratory experiments and a combination of various methodologies. The objective of this review article is to discuss the concept and consequences of polymerization shrinkage and shrinkage stress of composite resins and resin cements. Literature relating to polymerization shrinkage and shrinkage stress generation, research methodologies, and contributing factors are selected and reviewed. Clinical techniques that could reduce shrinkage stress and new developments on low-shrink dental materials are also discussed.

Keywords: Tooth; Sensitivity and Specificity; Composite Resins; Polymerization.

\section{Introduction}

The bonding strategies associated with esthetic and conservative properties of resin materials have increased their popularity in restorative dentistry. ${ }^{1}$ Direct composite restorations are one of the most prevalent medical interventions in the human body, with more than five hundred million composite restorations placed every year around the world. ${ }^{2}$ When indirect restorations are recommended, esthetic onlays and crowns bonded with resin cement are the first option. ${ }^{3}$ The optimal performance of all these direct and indirect restorations depend on proper polymerization of the resin component, which is characterized by transforming monomers into polymers, which is accompanied by volumetric reduction of the material. ${ }^{4}$

A polymer occupies less volume than the monomers, the effect of which is well known as polymerization shrinkage. During polymerization the distance between monomer chains is reduced when the weak van der Waals 
forces are converted into covalent bonds. ${ }^{5}$ A gradual increase in viscosity of the resin material also occurs during the conversion, resulting in loss of its fluidity (gel-point) and flowing ability (vitrification). ${ }^{4}$ Prior to vitrification, these materials are able to flow and partially relieve stresses. After the polymerizing material looses its ability to flow, its elastic properties increase and, consequently, any restraints on the polymerization shrinkage (for example by the bonding between restoration and tooth structure) will generate residual shrinkage stresses. ${ }^{67,8,9}$

Despite various developments in new restorative materials over the last years, drawbacks related to polymerization shrinkage of composites and resin cements remain a clinical problem. ${ }^{1,10,11}$ Typically, dental composites used in restorative procedures exhibit volumetric shrinkage ranging from less than $1 \%$ up to $6 \%$, depending on the formulation and curing conditions. ${ }^{1,0,12}$ Resin cements exhibit at least similar or even higher polymerization shrinkage values. ${ }^{11,13}$

A consequence of shrinkage stress can be debonding along the restoration/tooth interface or at the restoration margins, resulting in internal and marginal gaps, micro-cracking of either or both the restorative material and tooth structure, marginal stain cuspal movement (Figures 1 and 2). ${ }^{6,78,8,9,10,11}$ When indirect restorations are cemented to a vital tooth, polymerization shrinkage may result in postoperative sensitivity or marginal debonding that contributes to marginal staining, ${ }^{11}$ which is often erroneously used as a criterion for replacement of indirect and direct composite restorations (Figure 2C).
Several experimental methods have been developed to measure polymerization shrinkage of composites and resin cements. Most methodologies record total shrinkage, which include both pre- and post-gel shrinkage. In contrast, the strain gauge technique was proposed to isolate the post-gel shrinkage, which is more directly related to shrinkage stress development. Experimentally, the effects of polymerization shrinkage and shrinkage stress can be studied by a method such as micro-CT to measure internal gaps, while forces exerted by polymerization shrinkage can be measured using load cells. Shrinkage stress itself, however, cannot be measured directly because it is not a material property or physical response but a calculated engineering factor that

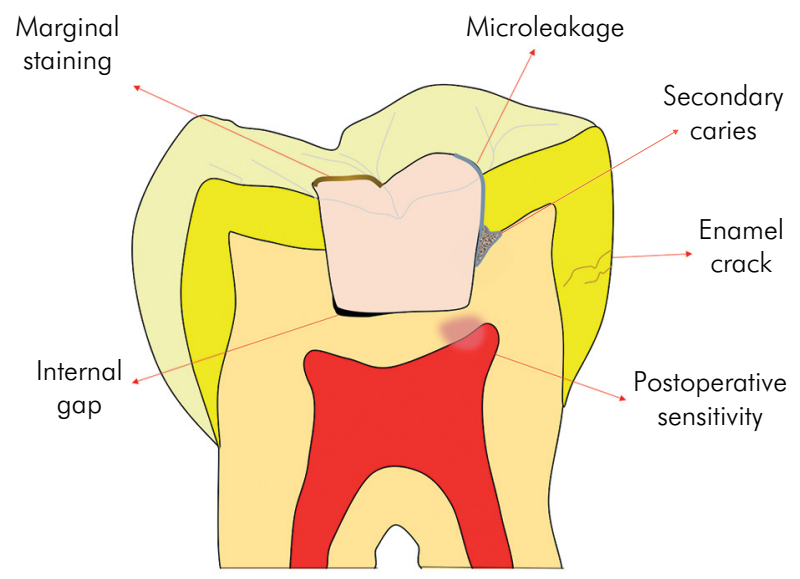

Figure 1. Schematic signs and symptomscaused by polymerization shrinkage (adaptated from Tantbirojn et al. ${ }^{16}$ ).
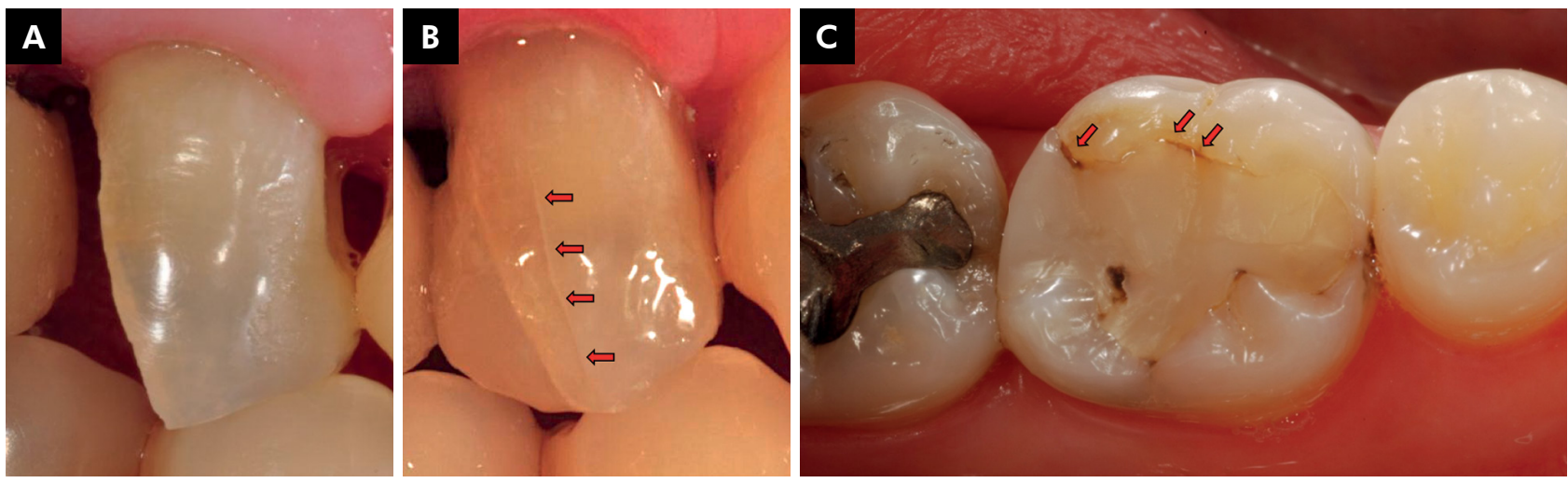

Figure 2. Clinical signs of polymerization shrinkage; A. Buccal cusp after deep caries removal showing no enamel crack; B. Enamel crack (red arrows) generated immediately after incremental filling composite resin restoration; C. Marginal staining (red arrows) of the restoration after 5 years in function. 
expresses the state within a material depending on local deformation and material properties. ${ }^{6}$ Shrinkage stress and stress distribution can be calculated using finite element analysis. ${ }^{6}$

The development of new resinous materials and the inevitable clinical signs and symptoms associated with polymerization shrinkage make this topic an important issue for clinicians and researchers. Therefore, this review article will focus on polymerization shrinkage, polymerization stress, their consequences, strategies used by companies and clinicians to minimize the effects, starting with discussion of a selection of methodologies that are used for shrinkage measurements.

\section{Methodology}

\section{Methods for measuring shrinkage}

Methods aimed at measuring volumetric changes during polymerization can be divided into those that measure total shrinkage and those that measure post-gel shrinkage (Figure 3). During polymerization, a resin transitions from a viscous liquid into a viscoelastic solid. The point at which the resin starts to develop elastic properties is defined as the gel-point, which corresponds with the point observed in polymer science where the insoluble polymer fraction starts to form. ${ }^{4}$ As polymerization proceeds beyond the gelpoint, vitrification is the point where the resin can be considered a solid. Depending on the restraints placed on shrinkage movements, stress can develop at any time during the polymerization reaction, but residual stresses only develop after development of elastic properties. Thus, the portion of the total shrinkage that causes residual stresses is defined as the post-gel shrinkage. Many methods have been developed to measure polymerization shrinkage of composites. These include water and mercury dilatometers ${ }^{14}$ transducer methods, ${ }^{15}$ and optical methods. ${ }^{16}$

\section{Methods for measuring shrinkage stress and its effects}

Methods described in the previous section aim to record total shrinkage, which includes both pre- and post-gel shrinkage. While useful for evaluating the volumetric changes resulting from polymerization,
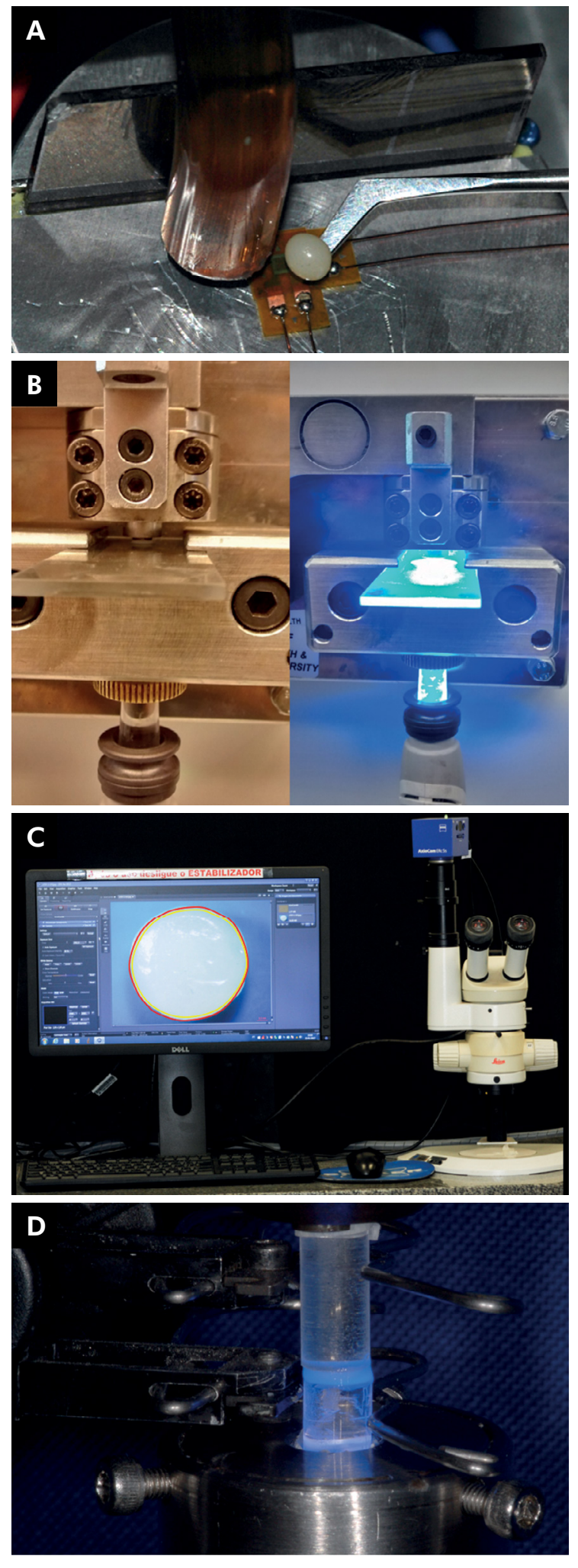

Figure 3. Experimental methods used for measuring polymerization shrinkage effect - A. Strain-gauge test for measuring post-gel shrinkage; B. Bioman for measuring shrinkage force; C. Optical method for measuring total shrinkage; D. Contraction stress using set-up with two opposing glass rods. 
they do not distinguish between materials with different rates of elastic modulus development. ${ }^{17}$ To measure the effect of the polymerization shrinkage on surrounding structures, other methods have been used, such as photoelastic analysis, ${ }^{18}$ shrinkage force via load cells, ${ }^{19,20}$ and cuspal deflection. ${ }^{8,10,21}$ Shrinkage stresses have also been analyzed using finite element methods ${ }^{9,11,12,22}$ and enamel crack tracking. ${ }^{10,23}$ Since different testing methods provide different information about shrinkage stress development, a more complete picture of the complex interactions during the polymerization process is likely obtained by a combination of different tests.

\section{Post-gel shrinkage using strain gauge}

A simple method to determine the post-gel shrinkage was developed by Sakaguchi et al. ${ }^{17}$ using a strain gauge technique. In this approach, a standardized volume of the material is placed on top of a (biaxial) strain gauge and shaped into a hemisphere approximately $1.5 \mathrm{~mm}$ high and $3-4 \mathrm{~mm}$ wide (Figure 3A). The strain gauges are connected in a quarter-bridge circuit with an internal reference resistance. A strain conditioner converts electrical resistance changes in the strain gauge into voltage changes, which are related to strains caused by the polymerization shrinkage. Since it takes some resin rigidity to cause the strain gauge deformation (strain), the measured strain is a post-gel shrinkage value. Just like strain, shrinkage is defined as the change in dimension (or volume) divided by the original dimension (or original volume). The linear strain value can be converted to percentage volumetric shrinkage by multiplying it by $300 \%$.

The strain output recorded during a post-gel shrinkage test results from at least three events: a. polymerization shrinkage of the composite; $b$. thermal expansion of the composite and strain gauge from heat generated by the polymerization exotherm; and c. thermal expansion of the composite and strain gauge from heat generated by the curing light. ${ }^{17}$ The thermal effect does not need to be considered when reporting the steady state strain after the heat has dissipated. However, the thermal effect does modify the shrinkage curve, particularly during the time when the material is exposed to the curing light. The thermal expansion due to the curing light could be eliminated by measuring the expansion of the cured resins and subtracting it from the original shrinkage curve, although it is likely that thermal effects from the curing light are also present under clinical conditions. This strain gauge method has been used for measuring the post-gel shrinkage of traditional composite resins, ${ }^{9,12,17}$ flowable composite resins, ${ }^{24,25,26}$ bulk fill composite resins, ${ }^{10}$ and resin cements. ${ }^{711}$ One limitation of this method is measuring highly flowable materials, because of the difficulty placing and maintaining samples with sufficient thickness on the strain gauge.

\section{Bioman method for measuring shrinkage force}

Watts et al. ${ }^{20}$ developed an apparatus designed specifically to measure polymerization shrinkage forces of light-cured dental composites (Figure 3B). The 'Bioman shrinkage-stress' instrument is based on a cantilever load-cell fitted with a rigid integral clamp. A circular steel rod with $10 \mathrm{~mm}$ diameter is held at one end of the apparatus, while the counterface is a removable glass plate. The distance between the glass plate and steel rod is adjusted (usually ranging from 0.8 to $1.2 \mathrm{~mm}$ ) to determine the $\mathrm{C}$-factor required for the experimental design. Prior to the experiments, the opposing surfaces of the glass and steel rod are sandblasted and/or silanated to allow proper bonding of composite which is inserted between these two surfaces. The light-activation of composite is performed through the lower glass plate. The rationale of this apparatus is that the shrinkage of composite causes slight displacement of the free end of the cantilever. The load signal emitted from cantilever load cell is recorded in realtime by a computer and a stress value is obtained by dividing the load by the disk area. A Bioman instrument has been used to determine kinetics of the effect of variations in filler particle size and shape. ${ }^{27}$ This method has been also used for characterizing new formulations of composite resins. ${ }^{28}$

\section{Crack propagation in a glass cavity}

This method is based on measuring the residual stress in a bonding substrate by using the increase in 
length of indentation cracks performed at the margin of a filled glass cavity. ${ }^{29,30}$ The cavity is prepared in glass-ceramic rods or soda-lime glass discs, materials with elastic modulus and fracture toughness similar to human enamel. After calculating the stress at the crack site and the distance between the indentation and cavity margin, radial tensile stresses are calculated at the bonded interface. ${ }^{25,29,30}$ Crack analysis has been used to calculate residual stresses produced by different photo activation methods ${ }^{29}$ and at different distances from the restoration margin. ${ }^{30}$ Braga et al., ${ }^{25}$ demonstrated that this method was effective for ranking composites according to their polymerization stress development. A limitation of this method is the recommended distance between the cavity limit and the indentation required to avoid chipping of the cavity edge during indentation. ${ }^{29}$ This method for calculating the stresses is a relatively simple technique requiring a conventional hardness tester. The method has clinical relevance for investigating enamel cracks near the margins and the formation of contraction gaps. ${ }^{29}$

\section{Optical method}

Tantbirojn et al. ${ }^{16}$ developed a new method using optical measurement in which the projected surface area of a sample is measured from images captured by a stereomicroscope using image analysis (Figure 3C). In the optical method, an uncured composite sample is placed on a nonstick silicone surface under a stereomicroscope. An image is taken before and after light-activation at the same magnification. Using image analysis software, the sample outlines before and after polymerization are determined, from which the change in projected surface area and hence free (unconstrained) polymerization shrinkage can be calculated. This method is simple, and can also be used to study long-term volumetric changes, such as the gradual compensation of polymerization shrinkage by hygroscopic expansion in humid environments. ${ }^{31}$ This method measures free shrinkage and is therefore less affected by specimen shape than shrinkage measurement methods that require specimen fixation.

\section{Universal Testing Machine method}

The universal testing machine method involves the use of steel, glass, or plastic rods connected to a load cell of a universal testing machine. ${ }^{19,32,33}$ The distance between the upper and lower rods is standardized and the composite resin is inserted and light activated. An extensometer records changes in distance between the rods and a shrinkage stress is calculated by dividing the axial force measured by the load cell by the bonded area (Figure 3D). The rod type, for example, steel or glass, has a significant influence on the results because they alter the compliance of the system..${ }^{19}$ Gonçalves et al. ${ }^{33}$ compared four different methods for calculating shrinkage stress, including the Bioman and universal testing machine, showed that both systems were in good agreement. However, the authors highlighted that direct comparison of polymerization stress data derived from different testing systems is not recommended.

\section{Cusp deflection}

Polymerization shrinkage can cause cuspal flexure, which is a detectable indication of the influence of internal stresses that are generated by the tooth substrate resisting shrinkage movement. ${ }^{21,22}$ The amount of cuspal flexure depends on the bonding interface quality, ${ }^{8}$ remaining tooth structure, ${ }^{34}$ and temperature and humidity. ${ }^{35}$ Cusp deflection can be measured using various methods, for example strain gauges (Figure 4A), which measure strains (deformation) at the external cuspal surfaces. ${ }^{8,9,10,35}$ Another simple method is the use of a digital micrometer to measure the distance between cusp tips before and after restoration. ${ }^{36}$ Cuspal flexure has also been measured using 3D scanning techniques. Using an optical scanner, the 3D surfaces of prepared and restored teeth were accurately aligned with dedicated software using stainless steel references. ${ }^{21,22,37}$ The amount of cuspal flexure was calculated from differences between the surfaces of the prepared and restored teeth. This method has also been used to measure how shrinkage deformation evolves over time, including the effect of hygroscopic expansion ${ }^{37}$ Recently, cusp deflection was measured using micro-CT scans of prepared and restored teeth. Since CT-scans also collect information about the internal structure of a restored tooth, it offers additional data for studying shrinkage stress. Both methods, using micro-CT or optical scanner, have high accuracy and measure the 


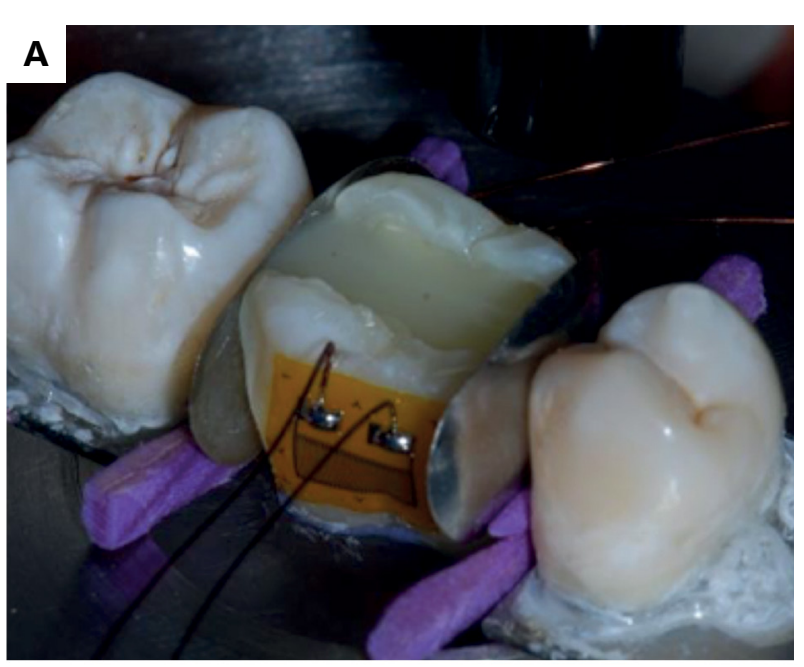

C

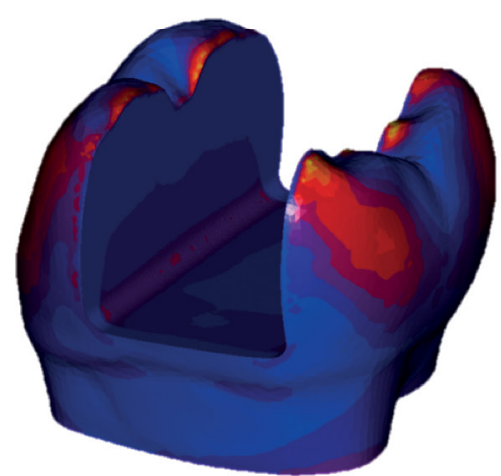

D
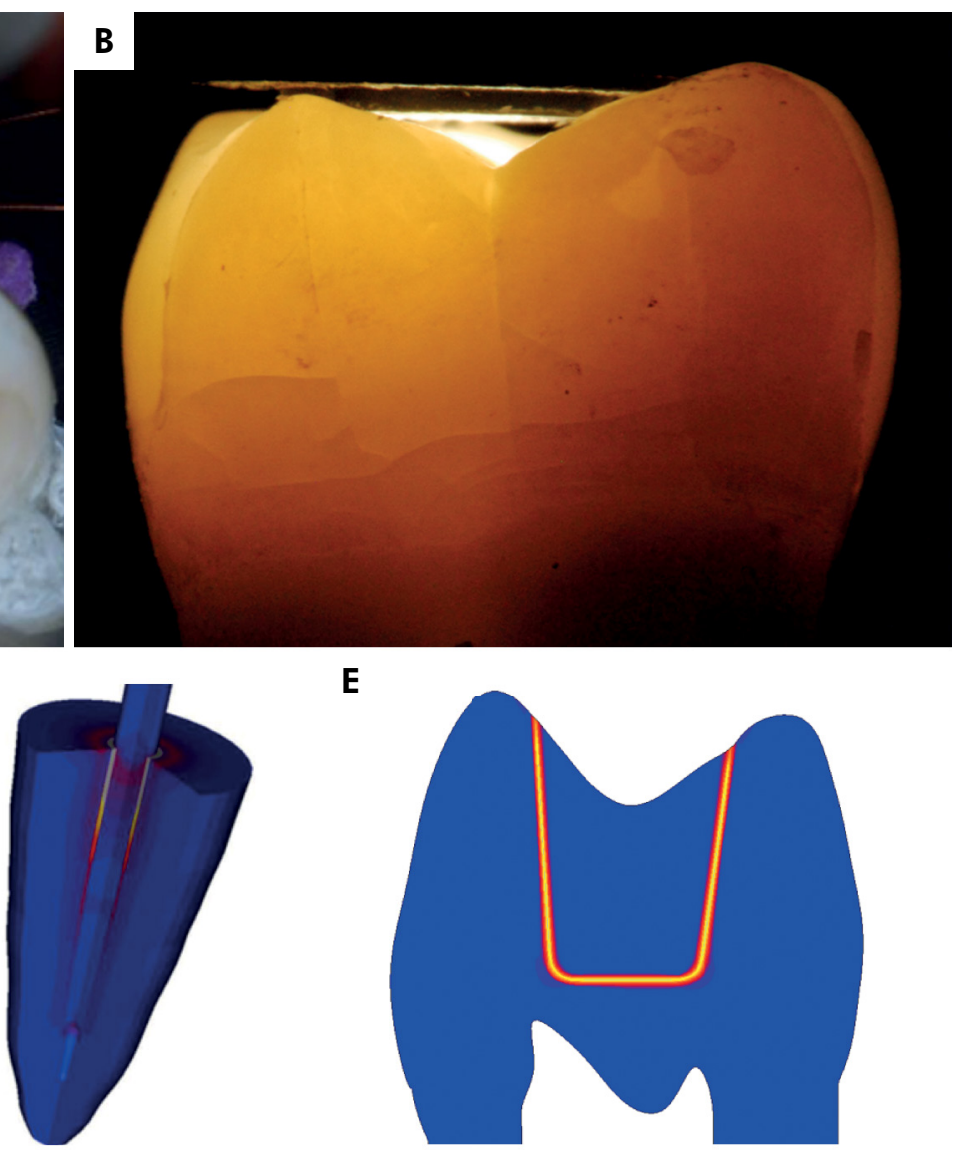

E

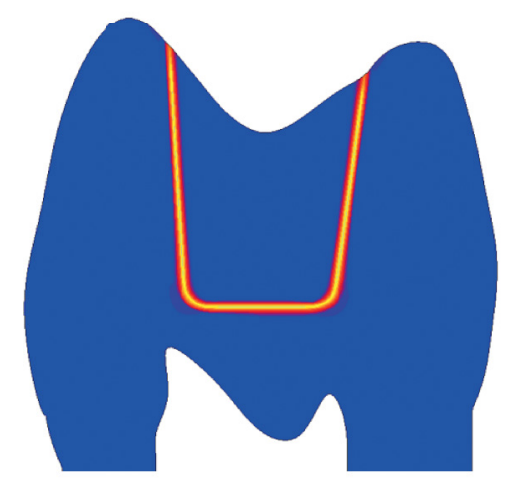

Figure 4. Experimental methods used for measuring polymerization shrinkage stress effect - A. strain-gauge used for measuring cusp deformation; B. transillumination of MOD cavity after incremental filling technique showing enamel crack; C. 3D finite element model of bulk fill restoration; D. Axisymmetric model of resin cementation of fiber post; $E$. 2D model of ceramic inlay cementation.

deformation in three dimensions over the whole tooth volume simultaneously.

\section{Enamel crack tracking}

Crack propagation has been associated with shrinkage stress and the resulting cusp deflection. Shrinkage induced enamel micro fracture reportedly occurs immediately after polymerization..$^{10}$ Another study reported a fracture line (enamel crack) in the cusp after a large MOD restoration was placed..$^{23}$ The fracture line corresponded with an area expected to have a relatively high cuspal strain. To detect the presence of enamel cracks in buccal and lingual cusps a transillumination technique can be used. In this technique, a tooth is transilluminated when intact, after cavity preparation and after restoration. Images of the sample are captured at $\times 1.5$ magnification under standardized conditions using a digital camera with
$105 \mathrm{~mm}$ macro lens (Figure 4B). The use of high intensity and focused LED light is recommended to properly perform the transillumination. Calibrated and blinded evaluators should carry out the evaluation of crack propagation. Enamel cracks can be characterized by the following ranking: (I) no cracks visible, (II) visible cracks smaller than $3 \mathrm{~mm}$, and (III) visible cracks larger than $3 \mathrm{~mm} \cdot{ }^{10,23}$ Recently the method was further improved by measuring the crack size and determining its location to better explain the shrinkage effects. This method can also be used for analysis of the effects of resin cementation of ceramic restorations.

\section{Finite Element Analysis (FEA)}

Finite element analysis (FEA) has become a valuable tool when examining the magnitude and distribution of shrinkage stresses. ${ }^{911,12,22}$ To calculate residual shrinkage stress in a tooth, a two-dimensional or 
three-dimensional finite element simulation can be carried out (Figures 4C, D and E).,12,16,38 Mechanical properties of the tooth substrate and restorative materials should be measured or carefully obtained from the literature, although the first approach is preferable. The Knoop hardness method is a convenient test to determine the elastic modulus of resin-based materials. ${ }^{11,12,35,39,40}$ Dynamic indentation is another viable method to identify variations in elastic modulus affected by experimental conditions. ${ }^{8,10}$ Shrinkage can be simulated in a finite element analysis using thermal analogy, because finite element software usually does not offer a dedicated 'shrinkage' option. Reducing the temperature for the simulated composite material will cause contraction, which can be scaled using the coefficient of thermal expansion to match the experimentally determined polymerization shrinkage values. ${ }^{12,40}$ Since the finite element program will determine the three-dimensional effects, linear shrinkage values can be entered as the coefficient of thermal expansion in combination with a $1^{\circ} \mathrm{C}$ drop in prescribed temperature. For shrinkage stress development it is important to apply the post-gel shrinkage value because total shrinkage values would contain the contraction component that does not cause shrinkage stress and would therefore overestimate the residual shrinkage stresses. Any FEA software program that includes options for thermal effects, such as Ansys (Ansys Inc, Canonsburg, PA, USA) or MSC.Marc (MSC Software Corporation, Santa Ana, CA, USA), should be able to simulate basic polymerization shrinkage. We used MSC.Marc in our research.

\section{Clinical techniques and their effect of shrinkage stress}

\section{Composite insertion technique}

Traditionally, for direct restorations, clinicians have inserted composite material incrementally because it was assumed to reduce shrinkage stresses while achieving proper polymerization. ${ }^{10,41}$ A popular approach is to restore a cavity in oblique increments to avoid bonding to opposite walls. This technique has been suggested to result in less cuspal flexure compared to a single increment based on tests carried out with aluminum blocks. ${ }^{42}$ The concept of oblique incrementation is based on a theory that the ratio of bonded and unbonded restoration surfaces ('C-factor') determines the shrinkage stress. ${ }^{43}$ According to this theory, reducing the $\mathrm{C}$-factor and producing one cusp deflection at a time would alleviate shrinkage stress. ${ }^{42}$ However, the C-factor concept is too simplistic to predict shrinkage stresses. Although the first increments can be inserted without bonding to the opposite walls, cuspal flexure is not avoided. Since each increment causes inward deformation of the cavity, increasing the number of increments used to fill a cavity results in higher cumulative cuspal deformation and thus stress. ${ }^{8,9}$ Moreover, subsequent layers of composite are required to fill the cavity, and eventually will bond to all walls. ${ }^{8}$ Thus, significant shrinkage stress in the tooth structure and along the bonded interfaces are still expected. Actually, placing composite in oblique increments causes stresses that can be even higher than would be obtained with a single increment fill (bulk filling) ${ }^{8,9,41}$ It is important to emphasize that regardless of the shrinkage stress, proper polymerization throughout a conventional composite depth is difficult to obtain when the material is light cured in a single increment. ${ }^{8}$ Reducing the conversion of composite would likely result in reduced stress due to lower volumetric shrinkage, but comes at the expense of the material properties.

Another variation on incremental insertion is using horizontal increments. ${ }^{12} \mathrm{~A}$ finite element analysis of a pre molar restoration using either oblique or horizontal increments found that using oblique increments produced lower residual shrinkage stress along the enamel/composite interface, while they were higher along the dentin/composite interface. ${ }^{12}$ Increments of $2 \mathrm{~mm}$ thickness seem to produce proper mechanical properties without increasing the residual shrinkage stress. Note also that unnecessarily increasing the number of increments could lead to a higher chance of incorporating voids and porosity.

\section{Modifying the light-activation protocol}

Modifying light-activation protocols, such as soft-start and pulse delay, have been advocated as an approach to reduce the shrinkage stress 
while maintaining proper degree of conversion of composite. ${ }^{44}$ The rationale is that starting the polymerization with low intensity (usually around $100 \mathrm{mw} / \mathrm{cm}^{2}$ ) produces a reduced amount of free-radicals with a slower polymerization, delaying the vitrification point of composite. ${ }^{45}$ The polymer vitrification occurs when the viscosity reaches high value, reducing the ability of a material to relieve stresses generated by the shrinkage. ${ }^{4}$ Thus, techniques used to modulate the light-activation are based on the concept that delaying the composite vitrification allows more relief of shrinkage stress by prolonging the period that composite can flow. For soft-start curing, the light-activation begins with a low irradiance for around 10 seconds followed by increased irradiance for the remaining period of light-activation to complete the polymerization process. ${ }^{4,45}$ Another technique, pulse delay protocol, is usually recommended only for the last increment and consists of light-activation with a low irradiance for shorter duration (such as 3 or 5 seconds) followed by a prolonged waiting period (approximately 5 minutes) before a final curing. ${ }^{44}$ This delay period allows stress relief to occur before the final light-curing with higher irradiance. Several laboratory studies have demonstrated improvements in marginal integrity of restorations using these protocols to modify light-activation without compromising mechanical properties of composites. ${ }^{44,45}$ Based on this concept, many light-curing units offer alternative regimens to emit light on pulsatile, ramp or soft-start modes.

On the other hand, these modified light-activation protocols may have limitations. Using low irradiance generates few chain growth centers during the polymerization reaction and results in more linear polymeric chains; which are more prone to degradation. ${ }^{46}$ Moreover, slower polymerization reaction might produce polymers with lower elastic modulus than those obtained under high irradiance. This lower elastic modulus may contribute to a reduction in shrinkage stress, but may increase the risk of failure under loading if accompanied with lower strength properties. ${ }^{47}$ An interesting study used an experimental set-up that allowed real-time measurement, within the same specimen, of shrinkage force development and conversion, which was used to compare light-activation with the soft-start, pulse-delay and continuous modes. ${ }^{48}$ The study reported that the reduction in shrinkage forces for soft-start and pulse delay modes was strongly affected by the lower conversion of composite. Moreover, more than $70 \%$ of the overall shrinkage force was generated after the composite reached the last $15 \%$ of conversion. This study also reported that the continuous irradiance resulted in lower shrinkage forces than the other modes at the same conversion, and suggested that a significant reduction in stress could only be reached by delaying the vitrification point. There is thus no consensus in the literature about the benefits of different light application protocols and little clinical data is available to show if such protocols provide significant benefits under clinical conditions. In one randomized prospective clinical study, for a 7-year follow-up, composite restorations cured with the soft-start or pulse delay protocol had failure rates of $27.9 \%$ and $24.4 \%$, respectively; while light-activating the composite with continuous irradiance resulted in failure rates of $17 \%{ }^{49}$

\section{Stress absorbing intermediate layer}

Besides volumetric shrinkage, shrinkage stress is also related to the elastic modulus of a material because a less rigid material (low modulus) has increased strain capacity. ${ }^{50}$ Based on this assumption, using a material with low elastic modulus as an intermediate layer under the composite have been advocated to reduce the shrinkage stress in a concept called 'elastic cavity wall'. ${ }^{50,51}$ Several studies have evaluated the use of thicker adhesive layers (usually non-solvated adhesives), glass ionomers, or flowable composites as a stress-absorbing layer. ${ }^{50,51,52,53,54}$ Flowable composites usually contain 20 to $25 \%$ less fillers than composites with regular viscosity, which reduces their elastic modulus close to those of resin-modified glass ionomers. However, reducing filler content of flowable composites means increasing the ratio of the resin matrix. Therefore the ability to deform and accommodate shrinkage stress could be offset by increasing volumetric shrinkage due to the higher resin matrix ratio. ${ }^{55}$ Although clinical evidence is limited, experimental studies 
demonstrated significant reduction in marginal leakage or improved marginal integrity using thicker adhesive layers, ${ }^{53}$ glass ionomer, ${ }^{52}$ or flowable composites $^{54}$ as intermediate layer under composite restorations. Reduction of cusp deflection was also reported when flowable composite ${ }^{54}$ or glass ionomer ${ }^{56}$ was placed under a composite with regular viscosity, although reduction in shrinkage stress was not apparent. ${ }^{51}$ Braga et al. ${ }^{50}$ reported that the effect of flowable composites as intermediate layer on stress reduction is limited and depends on the elastic modulus of lining material; while an indirect correlation between stress reduction and elastic modulus was observed. Clinical trial of placing a flowable composite as an intermediate layer did not exhibit a positive outcome, ${ }^{57}$ while using glass ionomer under a composite restoration increased the risk of restoration fractures. ${ }^{58}$ It is critical to emphasize that placement of glass ionomer liners as pulp protection material in deep cavities is still indicated..$^{59}$

\section{Use of Bulk Fill composite}

Incremental filling is time-consuming because multiple increments must be inserted and individually light-cured. Simple approaches are preferred by clinicians not only to save time but also to reduce potential for errors. Recently, the concept of bulk-fill composites was introduced, claiming that they could be light-activated in increments of up to 5-mm deep without compromising cure and while generating shrinkage stresses similar to those observed with traditional incrementally placed composites. The mechanisms used to achieve deeper polymerization and reduced stress are different among the bulk-fill composite manufacturers. Some manufacturers achieve deeper polymerization by using additional or more efficient photoinitiators such as bis-(4-methoxybenzoyl)diethyl-germane (Ivocerin). ${ }^{60}$ Others focus on increasing light transmission through the composites. The presence of pigments and refractive index mismatch between the organic matrix and fillers are the main factors causing reduction in light-transmission. ${ }^{61}$ Besides using fillers and monomers with similar refractive index, reducing filler content is another approach to increase the light-transmission and allow the polymerization at greater depths. ${ }^{62}$ However, lower filler content results in composite with lower mechanical properties, thus an additional increment of a regular viscosity composite is required to restore the occlusal surface. ${ }^{63}$ The advantages of flowable bulk-fill composite is improved adaptation to cavity walls and reduced shrinkage stress due to its lower elastic modulus. ${ }^{5}$

Reduction of shrinkage stress is another important claim for this new generation of bulk-fill composites. In fact, most bulk-fill composites available in the market did not represent any significant modification in monomeric composition. ${ }^{64}$ Among the bulk-fill composites with modifications to the organic matrix are addition of low-shrink or higher molecular weight monomers or stress-relieving additives. ${ }^{65}$ It was demonstrated that bulk-fill composites had reduced post-gel shrinkage and that restorations with bulk-fill composites had reduced cuspal deformation and shrinkage stress, and that the fracture resistance increased when compared with incrementally filled teeth. ${ }^{10}$ Clinically, few trials evaluating restorations with bulk-fill composites are available yet because these materials were only recently introduced. However, some early studies have demonstrated proper clinical behavior after 3 and 5 -year. ${ }^{66,67}$ It is important to emphasize that differences in strategies adopted by manufactures to obtain bulk-fill composites affect the behavior of these materials regarding depth of polymerization and generation of shrinkage stress and therefore results observed cannot be extrapolated to all materials that are classified by their manufacturer as bulk-fill. ${ }^{65}$

\section{Delayed light-activation of dual-cure cements}

Dual-cure resin cements are largely used to lute indirect restorations or fiber posts because they were designed to provide proper working time and curing, even in the absence of adequate light-activated polymerization. However, these advantages are not fully achieved and dual-cure cements usually require additional light-activation to achieve the desired mechanical properties, conversion, and bond strength. ${ }^{7,68,69}$ During the 
cementation of thick indirect restorations or fiber posts, the amount of light reaching the cement is significantly reduced due to light scattering, yet the light-curing procedure is important to stabilize the restoration/post during the first few minutes of the adhesive cementation process. ${ }^{70}$ In order to streamline the luting procedure, clinicians commonly light-activate dual-cured cements immediately after the placement of restoration/post and removal of the cement excess. However, the chemically activated polymerization reaction is hindered due to the fast increase in cement viscosity induced by the light-activation. In contrary, the slower chemically activated reaction is desired because it could be useful for reducing the shrinkage stress. ${ }^{47}$ A simple and practical strategy to reduce the shrinkage stress is to delay the moment that the light-activation is started. ${ }^{7,11,13}$ Delaying the light-activation allows polymer conversion to begin and progress at a slower pace to enhance stress relief as discussed previously. It has been demonstrated that a delay time of 3 or 5 minutes prior to light-activation of dual-cured cements can reduce the shrinkage stress and improve the bond strength ${ }^{7}$ without significantly altering the mechanical properties..$^{13,69,71}$ A delay in light activation of dual curing resin cement for cementing ceramic inlays reduced the post-gel shrinkage and decreased the shrinkage stresses at the pulpal floor, which may reduce post-operative sensitivity. ${ }^{11}$

\section{Modifications in the restorative composite formulation}

The issue of polymerization stress generated at the bonded interface has not only prompted the development of new restorative techniques, but also was the driver behind many the modifications proposed by the manufacturers to the organic matrix of resin composites. ${ }^{72}$ Most conventional materials contain dimethacrylate monomers in their composition, with average molecular weight varying from around $500 \mathrm{~g} / \mathrm{mol}$ (BisGMA: $512 \mathrm{~g} / \mathrm{mol}$; UDMA: $470 \mathrm{~g} / \mathrm{mol}$; BisEMA: $540 \mathrm{~g} / \mathrm{mol}$ ) to around $290 \mathrm{~g} / \mathrm{mol}$ (TEGDMA: $286 \mathrm{~g} / \mathrm{mol}$, commonly used as a low viscosity diluent). Over the past 15 years, much effort has been dedicated to developing low-shrinking formulations, either by virtue of using a ring-opening polymerization mechanism (as is the case with the product containg epoxide-based silorane monomers) or by using monomers with higher molecular weight (as is the case for composites using dimer-acid dimethacrylates, or DX-511, a monomer developed by DuPont, both with $\mathrm{Mw}$ greater than $800 \mathrm{~g} / \mathrm{mol}$ ), or even pre-polymerized additives. ${ }^{73}$ The structures for all of these monomers are shown in Figure 5. In the case of the ringopening monomers, the rationale for decreased shrinkage is their inherent lower molar shrinkage coefficient in comparison with methacrylates. ${ }^{74,75}$ This means that for equivalent initial volume and final degree of conversion, the monomer with the lower molar shrinkage coefficient will present less macroscopic shrinkage. ${ }^{74,75}$ Similarly, the higher the molecular weight of a single monomer unit, the less the shrinkage observed because for a given volume, there is less free volume among the higher molecular weight monomers to begin with, so the final volumetric shrinkage is less. ${ }^{76}$ Pre-polymerized additives, such as nanogels, can also be used to decrease shrinkage of restorative composites, as they reduce the initial concentration of available functional groups to react. ${ }^{73}$ In turn, again if the initial volume and the final conversion are similar for a given monomer, greater volumetric shrinkage is expected to translate into higher polymerization stress, and indeed a direct correlation has been established in experimental composites. ${ }^{76}$

In commercial materials, however, the comparisons are not as simple. There are many confounding factors that arise from other differences in formulation such as the initiator concentration, the filler loading, presence of other additives, amongst others, that make straight comparisons with methacrylates difficult, if not impossible. Moreover, stress generation depends not only on the shrinkage, but also on the degree of conversion and elastic modulus of the material, which in turn are also affected by variations in composition. ${ }^{76}$ In fact, one in vitro study evaluating different brands of low shrinkage composites has demonstrated that the lowest shrinking material did not necessarily present the lowest polymerization 

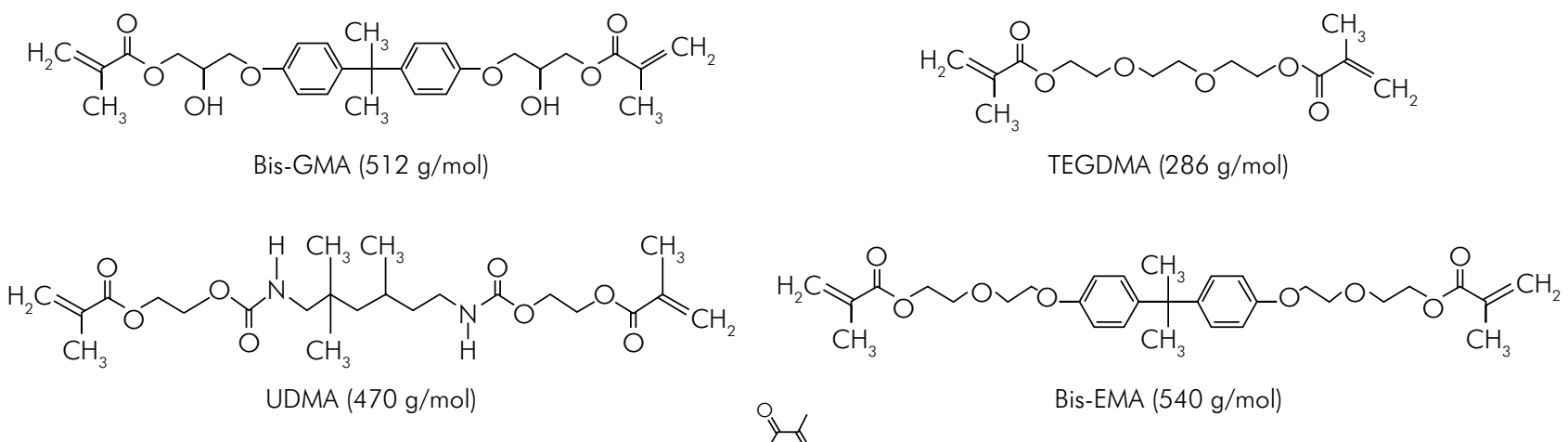

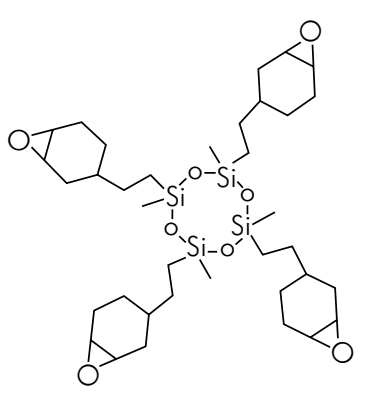

Silorane $(470 \mathrm{~g} / \mathrm{mol})$

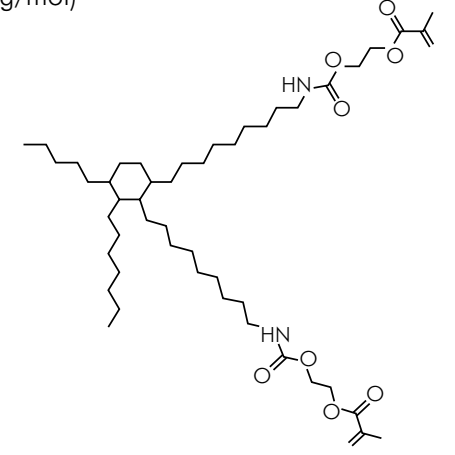

Dimer acid dimethacrylate $(870 \mathrm{~g} / \mathrm{mol})$
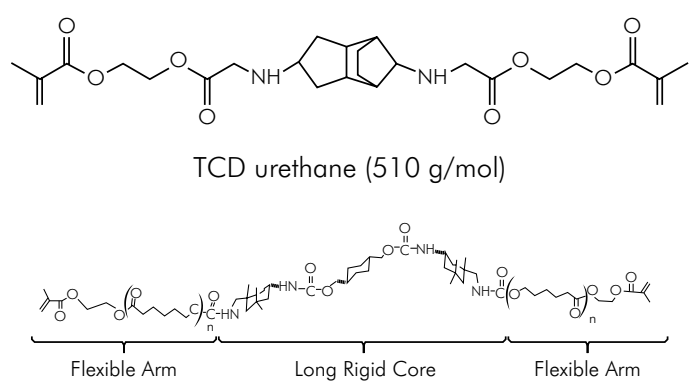

DX-51 $1(895 \mathrm{~g} / \mathrm{mol})$

Figure 5. Structural formula of base-monomers. Formulas provided by the respective manufacturers.

stress. ${ }^{32}$ For example, the silorane material presented significantly reduced shrinkage in relation to a methacrylate-based material from the same manufacturer, but statistically similar stress values, which was attributed to the much higher elastic modulus reached by the low-shrinkage material. Similarly, low shrink materials which presented lower stress also had much lower modulus. ${ }^{32}$ This evidences the complexity of this subject, and helps partially explain why to date no clinical evidence exists that low-shrinking materials perform significantly better than conventional ones in terms of improving restoration longevity. ${ }^{77,78,79}$ In the clinical situation, the presence of biofilm and the vast variation in patient's hygiene and dietary habits complicates matters even further. Indeed, even though the correlation between polymerization stress and gap formation has been well established, ${ }^{80}$ no clinical studies exist demonstrating such correlation in vivo.

There is evidence, however, for bacterial presence at the bottom of interfacial gaps in restorations placed in vitro and subjected to mechanical loading. ${ }^{81}$ As previously mentioned, the mere presence of the bacteria in the gap does not guarantee secondary caries will form, as that depends on many other host-derived factors, but this certainly increases the chances for restoration failure. ${ }^{81}$ The development of materials that can reduce stress directly, not merely based on shrinkage reduction mechanisms, has gained increased attention over the past few years. Thiol-ene-methacrylate systems have proven to be able to reduce stress without prejudice to the elastic modulus in vitro. ${ }^{82}$ The mechanism for stress reduction relies on the fact that thiol-ene polymerizations progress via step-growth, a process in which gelation and vitrification are not reached until much later in conversion, so any strain can be accommodated before it generates stresses at the interface. ${ }^{83,84}$ There are some disadvantages of using thiol-enes, such as a potential for decreased modulus in methacrylate polymerizations, and malodor of small molecule thiols. This can be circumvented by either decreasing the concentration of thiols in methacrylate polymerizations ${ }^{85}$ or by tethering thiol functionalities into pre-polymerized particles. ${ }^{86}$ In both those instances, chain-transfer reactions of the thiol to the methacrylate are able to delay gelation 
and vitrification and ultimately reduce stress, while increasing conversion and keeping the elastic modulus unchanged. ${ }^{86}$ Neither of those approaches has been advanced to a commercial material. Very recently, commercial materials based on stress-relieving moieties have been introduced in the market, both commercialized as bulk-fill materials. ${ }^{5}$ For at least one of them, the underlying technology relies on free-radical addition fragmentation groups, which are the active moieties in covalent adaptable networks. In summary, this mechanism promotes rearrangemente of the network connectivity without reducing the overall crosslinking density or the final mechanical properties of the composite, even in glassy networks. ${ }^{87}$ These materials are relatively new to the market, and therefore, in vitro studies and long-term clinical trials are scarce. Preliminary evaluations seem to demonstrate that they behave at least similarly to conventional restorative materials. ${ }^{67}$

\section{Summary statement}

In this review article we discussed what we need to know about polymerization shrinkage stress, which has concerned clinicians and researchers since resin-based materials were introduced in dental practice. We revealed how shrinkage stress and its clinical effects are determined by many factors to illustrate why this has been a much more complex topic than what may have appeared initially. Despite the obvious complexities, our review also shows how much progress has been made in the collective development of research techniques to better understand, predict, and develop shrinkage stress mitigation options and strategies that will continue to benefit clinicians and their patients.

\section{Acknowledments}

This study was supported by grants from FAPEMIG, CAPES and CNPq.

\section{References}

1. Mantri SP, Mantri SS. Management of shrinkage stresses in direct restorative light-cured composites: a review. J Esthet Restor Dent. 2013;25(5):305-13. https://doi.org/10.1111/jerd.12047

2. Heintze SD, Rousson V. Clinical effectiveness of direct class II restorations - a meta-analysis. J Adhes Dent. 2012;14(5):407-31. https://doi.org/10.3290/i.jad.a28390.

3. Runnacles P, Correr GM, Baratto Filho F, Gonzaga CC, Furuse AY. Degree of conversion of a resin cement light-cured through ceramic veneers of different thicknesses and types. Braz Dent J. 2014;25(1):38-42. https://doi.org/10.1590/0103-6440201302200

4. Odian G. Principles of polymerization. 3rd edition. New York: Wiley-Interscience; 1991

5. Kim RJ, Kim YJ, Choi NS, Lee IB. Polymerization shrinkage, modulus, and shrinkage stress related to tooth-restoration interfacial debonding in bulk-fill composites. J Dent. 2015;43(4):430-9. https://doi.org/10.1016/j.jdent.2015.02.002

6. Versluis A, Tantbirojn D. Relationship between shrinkage and stress. In: Daskalaki A, editor. Dental computing and applications: advanced techniques for clinical dentistry. Hershey, PA: IGI Global; 2009. p. 45-64.

7. Pereira RD, Valdívia $A D$, Bicalho $A A$, Franco $S D$, Tantbirojn $D$, Versluis $A$ et al. Effect of photoactivation timing on the mechanical properties of resin cements and bond strength of fiberglass post to root dentin. Oper Dent. 2015;40(5):E206-21. https://doi.org/10.2341/14-115-L

8. Bicalho AA, Pereira RD, Zanatta RF, Franco SD, Tantbirojn D, Versluis A et al. Incremental filling technique and composite material. Part I: cuspal deformation, bond strength, and physical properties. Oper Dent. 2014;39(2):E71-82. https://doi.org/10.2341/12-441-L

9. Bicalho AA, Valdívia AD, Barreto BC, Tantbirojn D, Versluis A, Soares CJ. Incremental filling technique and composite material. Part II: shrinkage and shrinkage stresses. Oper Dent. 2014;39(2):E83-92. https://doi.org/10.2341/12-442-L

10. Rosatto CM, Bicalho AA, Veríssimo C, Bragança GF, Rodrigues MP, Tantbirojn D, et al. Mechanical properties, shrinkage stress, cuspal strain and fracture resistance of molars restored with bulk-fill composites and incremental filling technique. J Dent. 2015;43(12):1519-28. https://doi.org/10.1016/i.jdent.2015.09.007

11. Soares CJ, Bicalho AA, Verissimo C, Soares P, Tantbirojn D, Versluis A. Delayed photo-activation effects on mechanical properties of dual cured resin cements and finite element analysis of shrinkage stresses in teeth restored with ceramic inlays. Oper Dent. 2016;41(5):491-500. https://doi.org/10.2341/15-090-L 
12. Soares CJ, Bicalho AA, Tantbiroin D, Versluis A. Polymerization shrinkage stresses in a premolar restored with different composite resins and different incremental techniques. J Adhes Dent. 2013;15(4):341-50. https://doi.org/10.3290/i.jad.a29012

13. Faria-e-Silva A, Boaro L, Braga R, Piva E, Arias V, Martins L. Effect of immediate or delayed light activation on curing kinetics and shrinkage stress of dual-cure resin cements. Oper Dent. 2011;36(2):196-204. https://doi.org/10.2341/10-153-L

14. Lai JH, Johnson AE. Measuring polymerization shrinkage of photo-activated restorative materials by a waterfilled dilatometer. Dent Mater. 1993;9(2):139-43. https://doi.org/10.1016/0109-5641(93)90091-4

15. Walls AW, McCabe JF, Murray JJ. The polymerization contraction of visible-light activated composite resins. J Dent. 1988;16(4):177-81. https://doi.org/10.1016/0300-5712(88)90032-2

16. Tantbirojn D, Pfeifer CS, Amini AN, Versluis A. Simple optical method for measuring free shrinkage. Dent Mater. 2015;31(11):1271-8. https://doi.org/10.1016/j.dental.2015.08.150

17. Sakaguchi RL, Versluis A, Douglas WH. Analysis of strain gage method for measurement of post-gel shrinkage in resin composites. Dent Mater. 1997;13(4):233-9. https://doi.org/10.1016/S0109-5641(97)80034-6

18. Ernst CP, Brand N, Frommator U, Rippin G, Willershausen $B$. Reduction of polymerization shrinkage stress and marginal microleakage using soft-start polymerization. J Esthet Restor Dent. 2003;15(2):93-103. https://doi.org/10.1111/j.1708-8240.2003.tb00323.x

19. Gonçalves F, Pfeifer CS, Meira JB, Ballester RY, Lima RG, Braga RR. Polymerization stress of resin composites as a function of system compliance. Dent Mater 2008;24(5):645-52. https://doi.org/10.1016/i.dental.2007.06.032

20. Watts DC, Marouf AS, Al-Hindi AM. Photo-polymerization shrinkage-stress kinetics in resin-composites: methods development. Dent Mater. 2003;19(1):1-11. https://doi.org/10.1016/S0109-5641(02)00123-9

21. Tantbirojn D, Pfeifer CS, Braga RR, Versluis A. Do low-shrink composites reduce polymerization shrinkage effects? J Dent Res. 2011;90(5):596-601. https://doi.org/10.1177/0022034510396217

22. Versluis A, Tantbirojn D, Pintado MR, DeLong R, Douglas WH. Residual shrinkage stress distributions in molars after composite restoration. Dent Mater. 2004;20(6):554-64. https://doi.org/10.1016/i.dental.2003.05.007

23. Batalha-Silva S, de Andrada MA, Maia HP, Magne P. Fatigue resistance and crack propensity of large MOD composite resin restorations: direct versus CAD/CAM inlays. Dent Mater. 2013;29(3):324-31. https://doi.org/10.1016/i.dental.2012.11.013

24. Alvarez-Gayosso C, Barceló-Santana F, GuerreroIbarra J, Sáez-Espínola G, Canseco-Martínez MA. Calculation of contraction rates due to shrinkage in lightcured composites. Dent Mater. 2004;20(3):228-35. https://doi.org/10.1016/S0109-5641(03)00097-6
25. Braga RR, Yamamoto T, Tyler K, Boaro LC, Ferracane JL, Swain MV. A comparative study between crack analysis and a mechanical test for assessing the polymerization stress of restorative composites. Dent Mater. 2012;28(6):632-41. https://doi.org/10.1016/i.dental.2012.02.008

26. Anatavara S, Sitthiseripratip K, Senawongse P. Stress relieving behaviour of flowable composite liners: A finite element analysis. Dent Mater J. 2016;35(3):369-78. https://doi.org/10.4012/dmi.2015-204

27. Satterthwaite JD, Maisuria A, Vogel K, Watts DC. Effect of resin-composite filler particle size and shape on shrinkage-stress. Dent Mater. 2012;28(6):609-14. https://doi.org/10.1016/j.dental.2012.01.007

28. Bacchi A, Nelson M, Pfeifer CS. Characterization of methacrylate-based composites containing thiourethane oligomers. Dent Mater. 2016;32(2):233-9. https://doi.org/10.1016/j.dental.2015.11.022

29. Yamamoto T, Ferracane JL, Sakaguchi RL, Swain MV. Calculation of contraction stresses in dental composites by analysis of crack propagation in the matrix surrounding a cavity. Dent Mater. 2009;25(4):543-50. https://doi.org/10.1016/i.dental.2008.10.008

30. Yamamoto T, Nishide A, Swain MV, Ferracane JL, Sakaguchi RL, Momoi Y. Contraction stresses in dental composites adjacent to and at the bonded interface as measured by crack analysis. Acta Biomater. 2011;7(1):417-23. https://doi.org/10.1016/j.actbio.2010.07.040

31. Suiter EA, Watson LE, Tantbirojn D, Lou JS, Versluis A. Effective expansion: balance between shrinkage and hygroscopic expansion. J Dent Res 2016;95(5): 543-9. https://doi.org/10.1177/0022034516633450

32. Boaro LC, Gonçalves F, Guimarães TC, Ferracane JL, Versluis A, Braga RR. Polymerization stress, shrinkage and elastic modulus of current low-shrinkage restorative composites. Dent Mater. 2010;26(12):1144-50. https://doi.org/10.1016/i.dental.2010.08.003

33. Gonçalves F, Boaro LC, Ferracane JL, Braga RR. A comparative evaluation of polymerization stress data obtained with four different mechanical testing systems. Dent Mater. 2012;28(6):680-6. https://doi.org/10.1016/i.dental.2012.03.004

34. González-López S, De Haro-Gasquet F, Vílchez-Díaz MA, Ceballos L, Bravo M. Effect of restorative procedures and occlusal loading on cuspal deflection. Oper Dent. 2006;31(1):33-8. https://doi.org/10.2341/04-165

35. Bicalho AA, de Souza SJ, de Rosatto CM, Tantbirojn D, Versluis A, Soares CJ. Effect of temperature and humidity on post-gel shrinkage, cusp deformation, bond strength and shrinkage stress - Construction of a chamber to simulate the oral environment. Dent Mater. 2015;31(12):1523-32. https://doi.org/10.1016/i.dental.2015.09.023

36. Behery H, El-Mowafy O, El-Badrawy W, Saleh B, Nabih S. Cuspal deflection of premolars restored with bulk-fill composite resins. J Esthet Restor Dent. 2016;28(2):122-30. https://doi.org/10.1111/jerd.12188 
37. Meriwether LA, Blen BJ, Benson JH, Hatch RH, Tantbirojn D, Versluis A. Shrinkage stress compensation in composite-restored teeth: relaxation or hygroscopic expansion? Dent Mater. 2013;29(5):573-9. https://doi.org/10.1016/i.dental.2013.03.006

38. Versluis A, Tantbirojn D, Douglas WH. Do dental composites always shrink toward the light? J Dent Res. 1998;77(6):1435-45. https://doi.org/10.1177/00220345980770060801

39. Marshall DB, Noma T, Evans AG. A simple method for determining elastic-modulus-to-hardness ratios using Knoop indentation measurements. J Am Ceram Soc. 1982;65:C175-6. https://doi.org/10.1111/j.1151-2916.1982.tb10357.x

40. Versluis A, Tantbirojn D, Douglas WH. Distribution of transient properties during polymerization of a light-initiated restorative composite. Dent Mater. 2004;20(6):543-53. https://doi.org/10.1016/i.dental.2003.05.006

41. Versluis A, Douglas WH, Cross M, Sakaguchi RL. Does an incremental filling technique reduce polymerization shrinkage stresses? J Dent Res. 1996;75(3):871-8. https://doi.org/10.1177/00220345960750030301

42. Park J, Chang J, Ferracane J, Lee IB. How should composite be layered to reduce shrinkage stress: incremental or bulk filling? Dent Mater. 2008;24(11):1501-5. https://doi.org/10.1016/i.dental.2008.03.013

43. Feilzer AJ, De Gee AJ, Davidson CL. Setting stress in composite resin in relation to configuration of the restoration. J Dent Res 1987;66:1636-9. https://doi.org/10.1177/00220345870660110601

44. Tauböck TT, Feilzer AJ, Buchalla W, Kleverlaan CJ, Krejci I, Attin T. Effect of modulated photo-activation on polymerization shrinkage behavior of dental restorative resin composites. Eur J Oral Sci. 2014;122(4):293-302. https://doi.org/10.1111/eos.12139

45. Silikas N, Eliades $G$, Watts DC. Light intensity effects on resin-composite degree of conversion and shrinkage strain. Dent Mater. 2000;16(4):292-6. https://doi.org/10.1016/S0109-5641(00)00020-8

46. Asmussen E, Peutzfeldt A. Influence of pulse-delay curing on softening of polymer structures. J Dent Res. 2001;80(6):1570-3. https://doi.org/10.1177/00220345010800061801

47. Feng L, Suh BI. A mechanism on why slower polymerization of a dental composite produces lower contraction stress. J Biomed Mater Res B Appl Biomater. 2006;78(1):63-9. https://doi.org/10.1002/jbm.b.30453

48. Lu H, Stansbury JW, Bowman CN. Impact of curing protocol on conversion and shrinkage stress. J Dent Res. 2005;84(9):822-6. https://doi.org/10.1177/154405910508400908

49. Dijken JW, Pallesen U. A 7-year randomized prospective study of a one-step self-etching adhesive in non-carious cervical lesions. The effect of curing modes and restorative material. J Dent. 2012;40(12):1060-7. https://doi.org/10.1016/i.jdent.2012.08.017

50. Braga RR, Hilton TJ, Ferracane JL. Contraction stress of flowable composite materials and their efficacy as stressrelieving layers. J Am Dent Assoc. 2003;134(6):721-8. https://doi.org/10.14219/jada.archive.2003.0258
51. Oliveira LC, Duarte S Jr, Araujo CA, Abrahão A. Effect of low-elastic modulus liner and base as stress-absorbing layer in composite resin restorations. Dent Mater. 2010;26(3):e159-69. https://doi.org/10.1016/i.dental.2009.11.076

52. Kemp-Scholte CM, Davidson CL. Complete marginal seal of Class $\mathrm{V}$ resin composite restorations effected by increased flexibility. J Dent Res. 1990;69(6):1240-3. https://doi.org/10.1177/00220345900690060301

53. Choi KK, Condon JR, Ferracane JL. The effects of adhesive thickness on polymerization contraction stress of composite. J Dent Res. 2000;79(3):812-7. https://doi.org/10.1177/00220345000790030501

54. Cara RR, Fleming GJ, Palin WM, Walmsley AD, Burke FJ. Cuspal deflection and microleakage in premolar teeth restored with resin-based composites with and without an intermediary flowable layer. J Dent. 2007;35(6):482-9. https://doi.org/10.1016/i.jdent.2007.01.005

55. Miyasaka T, Okamura H. Dimensional change measurements of conventional and flowable composite resins using a laser displacement sensor. Dent Mater J. 2009;28(5):544-51. https://doi.org/10.4012/dmi.28.544

56. Pereira R, Bicalho AA, Franco SD, Tantbirojn D, Versluis A, Soares CJ. Effect of restorative protocol on cuspal strain and residual stress in endodontically treated molars. Oper Dent. 2016;41(1):23-33. https://doi.org/10.2341/14-178-L

57. Boeckler A, Schaller HG, Gernhardt CR. A prospective, double-blind, randomized clinical trial of a one-step, self-etch adhesive with and without an intermediary layer of a flowable composite: a 2-year evaluation. Quintessence Int. 2012;43(4):279-86.

58. Opdam NJ, Bronkhorst EM, Roeters JM, Loomans BA. Longevity and reasons for failure of sandwich and total-etch posterior composite resin restorations. J Adhes Dent. 2007;9(5):469-75.

59. Costa CA, Ribeiro AP, Giro EM, Randall RC, Hebling J. Pulp response after application of two resin modified glass ionomer cements (RMGICs) in deep cavities of prepared human teeth. Dent Mater. 2011;27(7):e158-70. https://doi.org/10.1016/i.dental.2011.04.002

60. Menees TS, Lin CP, Kojic DD, Burgess JO, Lawson NC. Depth of cure of bulk fill composites with monowave and polywave curing lights. Am J Dent. 2015;28(6):357-61.

61. Shortall AC, Palin WM, Burtscher P. Refractive index mismatch and monomer reactivity influence composite curing depth. J Dent Res 2008;87(1):84-8. https://doi.org/10.1177/154405910808700115

62. Fujita K, Ikemi T, Nishiyama N. Effects of particle size of silica filler on polymerization conversion in a light-curing resin composite. Dent Mater. 2011;27(11):1079-85. https://doi.org/10.1016/i.dental.2011.07.010

63. Tomaszewska IM, Kearns JO, Ilie N, Fleming GJ. Bulk fill restoratives: to cap or not to cap: that is the question? J Dent. 2015;43(3):309-16. https://doi.org/10.1016/i.jdent.2015.01.010 
64. Alshali RZ, Salim NA, Sung R, Satterthwaite JD, Silikas N. Qualitative and quantitative characterization of monomers of uncured bulk-fill and conventional resin-composites using liquid chromatography/mass spectrometry. Dent Mater. 2015;31(6):711-20. https://doi.org/10.1016/j.dental.2015.03.010

65. Al Sunbul H, Silikas N, Watts DC. Polymerization shrinkage kinetics and shrinkage-stress in dental resin-composites. Dent Mater. 2016;32(8):998-1006. https://doi.org/10.1016/i.dental.2016.05.006

66. Dijken JW, Pallesen U. A randomized controlled three year evaluation of "bulk-filled" posterior resin restorations based on stress decreasing resin technology. Dent Mater. 2014;30(9):e245-51. https://doi.org/10.1016/i.dental.2014.05.028

67. Dijken JW, Pallesen U. Posterior bulk-filled resin composite restorations: A 5-year randomized controlled clinical study. J Dent. 2016;51:29-35. https://doi.org/10.1016/i.jdent.2016.05.008

68. Faria-e-Silva AL, Fabião MM, Arias VG, Martins LR. Activation mode effects on the shear bond strength of dual-cured resin cements. Oper Dent. 2010;35(5):515-21. https://doi.org/10.2341/10-051-L

69. Faria-e-Silva AL, Piva E, Lima GS, Boaro LC, Braga RR, Martins LR. Effect of immediate and delayed light activation on the mechanical properties and degree of conversion in dual-cured resin cements. J Oral Sci. 2012;54(3):261-6. https://doi.org/10.2334/josnusd.54.261

70. Faria-e-Silva AL, Mendonça AA, Garcez RM, Oliveira AS, Moreira AG, Moraes RR. Adhesion strategy and early bond strengths of glass-fiber posts luted into root canals. Braz Oral Res. 2012;26(5):485-7. https://doi.org/10.1590/S1806-83242012005000017

71. Faria-e-Silva AL, Peixoto AC, Borges MG, Menezes MS, Moraes RR. Immediate and delayed photoactivation of self-adhesive resin cements and retention of glass-fiber posts. Braz Oral Res. 2014;28:28. https://doi.org/10.1590/S1806-83242014.50000005.

72. Moszner N, Salz U Recent developments of new components for dental adhesives and composites. Macromol Mater Eng. 2007;292(3):245-71. https://doi.org/10.1002/mame.200600414

73. Moraes RR, Garcia JW, Barros MD, Lewis SH, Pfeifer CS, Liu J et al. Control of polymerization shrinkage and stress in nanogel-modified monomer and composite materials. Dent Mater. 2011;27(6):509-19. https://doi.org/10.1016/i.dental.2011.01.006

74. Patel MP, Braden M, Davy KW. Polymerization shrinkage of methacrylate esters. Biomaterials. 1987;8(1):53-6. https://doi.org/10.1016/0142-9612(87)90030-5

75. Patel MP, Braden M. Cross-linking and ring opening during polymerization of heterocyclic methacrylates and acrylates. Biomaterials. 1989;10(4):277-80. https://doi.org/10.1016/0142-9612(89)90106-3

76. Pfeifer CS, Ferracane JL, Sakaguchi RL, Braga RR. Factors affecting photopolymerization stress in dental composites. J Dent Res. 2008;87(11):1043-7. https://doi.org/10.1177/154405910808701114

77. Baracco B, Perdigão J, Cabrera E, Ceballos L. Two-year clinical performance of a low-shrinkage composite in posterior restorations. Oper Dent. 2013;38(6):591-600. https://doi.org/10.2341/12-364-C

78. Magno MB, Nascimento GC, Rocha YS, Ribeiro BD, Loretto SC, Maia LC. Silorane-based composite resin restorations are not better than conventional composites: a meta-analysis of clinical studies. J Adhes Dent. 2016;18(5):375-386. https://doi.org/10.3290/i.jad.a36916

79. Walter R, Boushell LW, Heymann HO, Ritter AV, Sturdevant JR, Wilder AD Jr et al. Three-year clinical evaluation of a silorane composite resin. J Esthet Restor Dent. 2014;26(3):179-90. https://doi.org/10.1111/jerd.12077

80. Boaro LC, Fróes-Salgado NR, Gajewski VE, Bicalho AA, Valdivia $A D$, Soares $C J$ et al. Correlation between polymerization stress and interfacial integrity of composites restorations assessed by different in vitro tests. Dent Mater. 2014;30(9):984-92. https://doi.org/10.1016/i.dental.2014.05.011

81. Khrostenko D, Salehi S, Naleway SE, Hilton TJ, Ferracane JL, Mitchell JC et al. Cyclic mechanical loading promotes bacterial penetration along composite restoration marginal gaps. Dent Mater. 2015;31(6):702-10. https://doi.org/10.1016/i.dental.2015.03.011

82. Carioscia JA, Lu H, Stanbury JW, Bowman $\mathrm{CN}$. Thiol-ene oligomers as dental restorative materials. Dent Mater. 2005;21(12):1137-43. https://doi.org/10.1016/i.dental.2005.04.002

83. Cramer NB, Couch CL, Schreck KM, Carioscia JA, Boulden JE, Stansbury JW et al. Investigation of thiol-ene and thiol-ene-methacrylate based resins as dental restorative materials. Dent Mater. 2010;26(1):21-8. https://doi.org/10.1016/i.dental.2009.08.004

84. Lu H, Carioscia JA, Stansbury JW, Bowman CN. Investigations of step-growth thiol-ene polymerizations for novel dental restoratives. Dent Mater. 2005;21(12):1129-36. https://doi.org/10.1016/i.dental.2005.04.001

85. Pfeifer CS, Wilson ND, Shelton ZR, Stansbury JW. Delayed gelation through chain-transfer reactions: mechanism for stress reduction in methacrylate networks. Polymer (Guildf). 2011;52(15):3295-303. https://doi.org/10.1016/i.polymer.2011.05.034

86. Bacchi A, Pfeifer CS. Rheological and mechanical properties and interfacial stress development of composite cements modified with thio-urethane oligomers. Dent Mater. 2016;32(8):978-86. https://doi.org/10.1016/i.dental.2016.05.003

87. Park HY, Kloxin CJ, Scott TF, Bowman CN. Covalent adaptable networks as dental restorative resins: stress relaxation by addition-fragmentation chain transfer in allyl sulfide-containing resins. Dent Mater. 2010;26(10):1010-6. https://doi.org/10.1016/j.dental.2010.06.007 